The Biochemical Journal, Vol. 91, No. 1

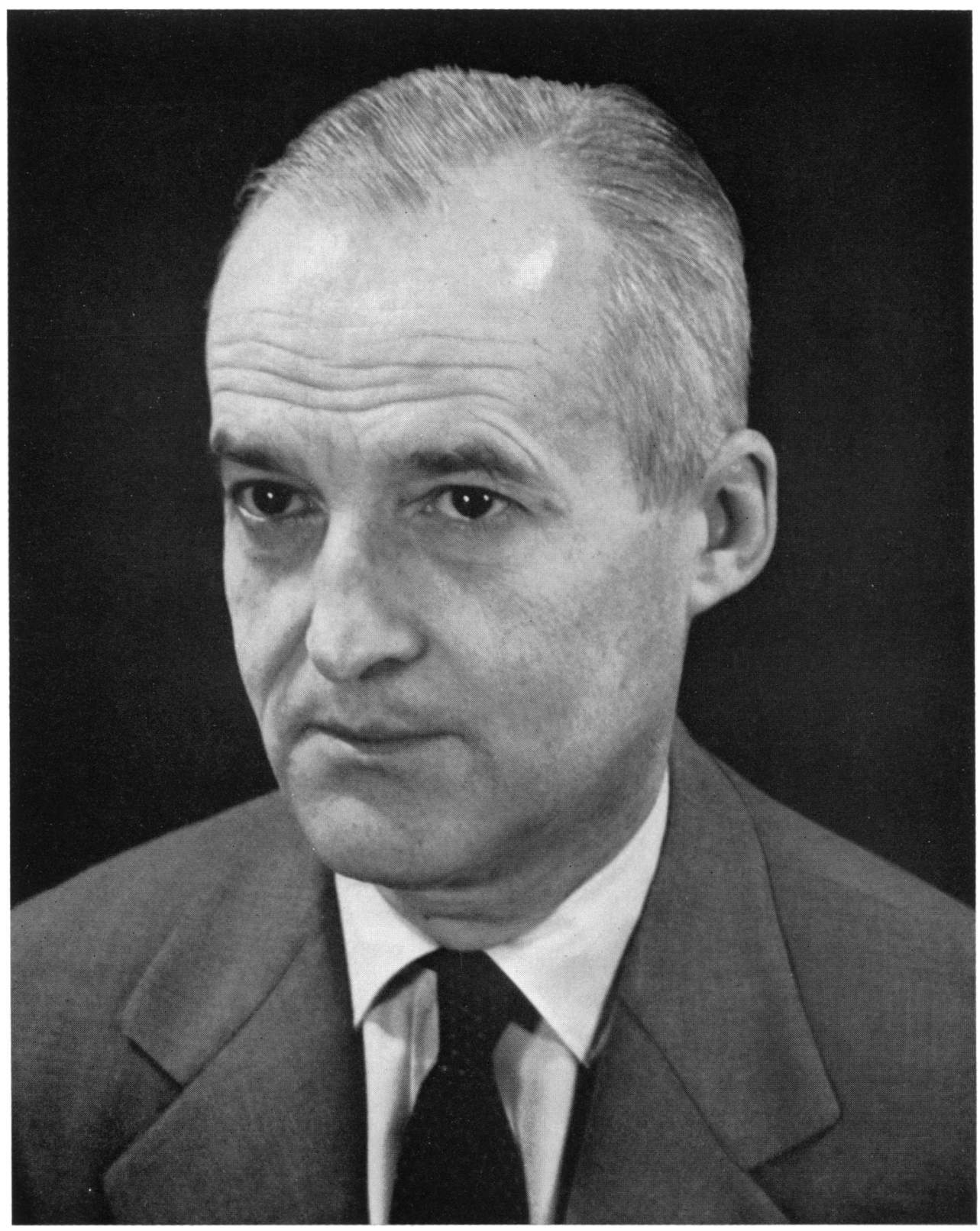

LUIS F. LELOIR 


\title{
Nucleoside Diphosphate Sugars and Saccharide Synthesis
}

\author{
By LUIS F. LELOIR
}

\author{
THE FOURTH HOPKINS MEMORIAL LECTURE \\ Delivered at a meeting of The Biochemical Society on 18 July 1963 in the Headington College \\ of Technology, Oxford
}

The invitation to give the Hopkins Memorial Lecture is an honour that I deeply appreciate. In 1935 I had the privilege of working at the Cambridge Biochemical Laboratory, when Sir Frederick was the director. It was then that I met him and learnt to admire his clarity of mind and generosity. The Biochemical Laboratory was one of the most active biochemical research centres in the world and the workers trained there have been important in the development of biochemistry in Great Britain and also in many other parts of the world.

The work of our group in Buenos Aires (Caputto, Cardini, Paladini, Trucco, Cabib, Pontis, Goldemberg, Olavarría etc.) on nucleoside diphosphate sugars originated in a rather simple investigation. Dr Caputto, who (in 1945) had also been trained in the Biochemical Laboratory and had done some work on the mammary gland, came to Buenos Aires and together we set out to work on lactose synthesis. Having failed to obtain any results with mammary-gland extract, we thought we might obtain some information by studying the utilization of lactose by micro-organisms. The yeast Saccharomyces fragilis when grown on lactose ferments the latter at a higher rate than a mixture of glucose and galactose (Caputto, Leloir \& Trucco, 1948). This fact has not been studied further and today would be attributed to a selective permeability of lactose. To investigate the problem we prepared extracts of $S$. fragilis and found that they catalysed galactose phosphorylation with ATP, giving galactose 1-phosphate (Trucco, Caputto, Leloir \& Mittelman, 1948). This substance had already been isolated by Kosterlitz (1943) (who worked at the Biochemical Laboratory in 1939) from the liver of galactose-fed rabbits.

The next step was the study of the fate of galactose 1-phosphate. It was found to be con-

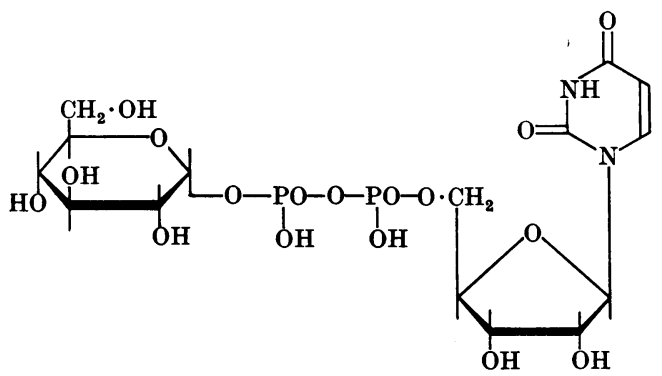

Uridine diphosphate glucose

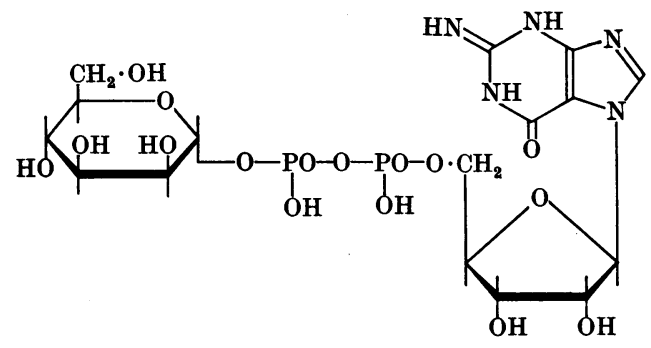

Guanosine diphosphate mannose

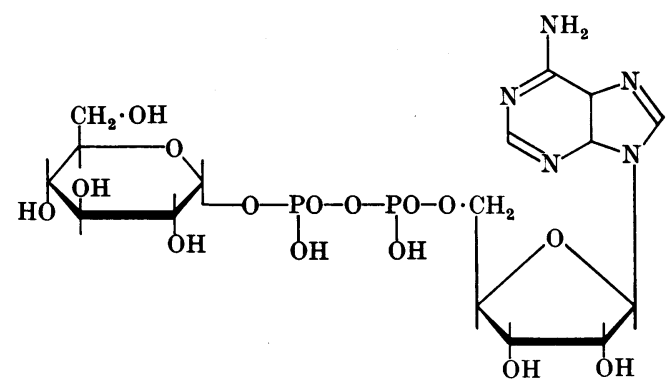

Adenosine diphosphate glucose

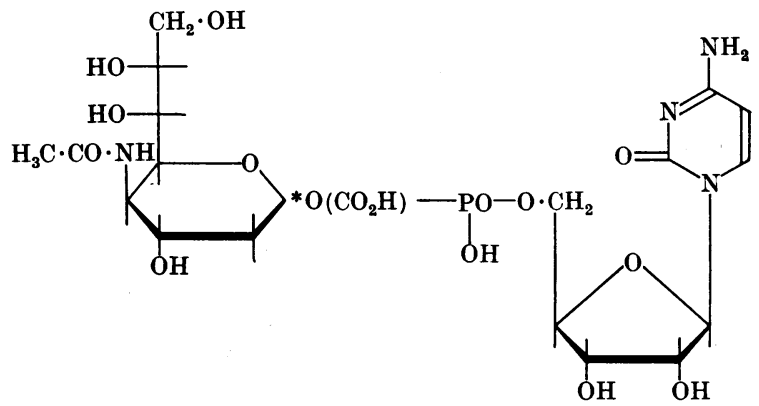

Cytosine monophosphate $N$-acetylneuraminic acid

Fig. 1. Examples of nucleoside phosphate sugars. The configuration of the linkage marked * is not known (Roseman, 1962a). 
verted into glucose 6-phosphate and it was fortunate that in such a simple reaction two cofactors turned out to be necessary. This fact made the initial studies very confusing, but eventually the two cofactors were isolated and their structures elucidated. One was glucose 1,6-diphosphate (Caputto, Leloir, Trucco, Cardini \& Paladini, 1948; Leloir, Trucco, Cardini, Paladini \& Caputto, 1948; Cardini, Paladini, Caputto, Leloir \& Trucco, 1949) and the other UDP-glucose (Cardini, Paladini, Caputto \& Leloir, 1950; Caputto, Leloir, Cardini \& Paladini, 1950). The structures of UDP-glucose and some related nucleoside diphosphate sugars are shown in Fig. 1.

At about the same time Park \& Johnson (1949) started to work on some compounds that accumulate in Staphylococcus aureus treated with penicillin. These compounds were later (Park, 1952) identified as UDP-acetylmuramic acid joined to amino acids. Since then the number of known nucleoside diphosphate sugars has grown rapidly. The first compounds to be found were uridine derivatives; then one of guanosine was isolated (Cabib \& Leloir, 1954), and subsequently derivatives of cytidine, adenosine and deoxythymidine became known. Nucleoside diphosphate sugars containing deoxyadenosine, deoxyguanosine and deoxycytidine have not been detected yet, but it is likely that they will be found soon. As to the sugar moiety, it may be represented by typical monosaccharides, amino sugars, uronic acids, deoxyhexoses or complex saccharides, and in some cases polyhydroxy compounds that are related to carbohydrates, such as ribitol, glycerol (Baddiley, 1962) or phosphoglyceric acid (Hashimoto, Tatibana, Ishii \& Yoshikawa, 1961). Different combinations and permutations of the bases and sugars give rise to many compounds, so that at least 44 have been described up to now (Cabib, 1963). These substances may undergo several types of enzymic reactions, e.g. the synthesis from the sugar 1-phosphates, destruction by phosphorolysis, different transformations of the sugar moieties and many types of transfer reaction.

\section{Biosynthesis from sugar 1-phosphates}

The synthesis of many nucleoside diphosphate sugars is carried out by enzymes that catalyse reactions of the following type:

Nucleoside triphosphate + sugar 1-phosphate $\rightleftharpoons$ nucleoside diphosphate sugar + inorganic pyrophosphate

The first of these enzymes to be discovered (Munch-Petersen, Kalckar, Cutolo \& Smith, 1953) catalyses the reaction:

UTP + glucose 1-phosphate

$\rightleftharpoons$ UDP-glucose + inorganic pyrophosphate
Many other similar reactions have been described since then. These lead to the synthesis of the following compounds: UDP-galactose (Fig. 1) (Kalckar, Braganca \& Munch-Petersen, 1953), UDP-acetylglucosamine (Smith, Munch-Petersen \& Mills, 1953; Mills, Ondarza \& Smith, 1954), UDP-glucosamine (Maley, Maley \& Lardy, 1956), GDP-mannose (Munch-Petersen, 1956), ADPglucose (Espada, 1962), thymidine 5'-diphosphate (TDP)-glucose (Kornfeld \& Glaser, 1961; Pazur \& Shuey, 1961), CDP-ribitol, CDP-glycerol (Shaw, 1962), TDP-acetylglucosamine (Kornfeld \& Glaser, 1962), UDP-D-xylose, UDP- $\beta$-L-arabinose (Neufeld, Ginsburg, Putman, Fanshier \& Hassid, 1957), GDP-glucose (Carlson \& Hansen, 1961) etc.

A somewhat similar reaction leads to the synthesis of a compound that is related to nucleoside diphosphate sugars but has only one phosphate group. This is CMP-neuraminic acid (Fig. 1) (Roseman, 1962 $a$; Warren \& Blacklow, 1962), the synthesis of which occurs as follows:

CTP + neuraminic acid $\rightarrow$ CMP-neuraminic acid + inorganic pyrophosphate

\section{Phosphorolysis of nucleoside diphosphate sugars}

Carminatti \& Cabib (1961) found an enzyme in yeast that catalyses the reaction:

GDP-mannose + inorganic phosphate

$$
\rightarrow \text { GDP + mannose 1-phosphate }
$$

When the reaction was carried out with radioactive inorganic phosphate the radioactivity was recovered in the terminal phosphate of GDP. The enzyme was found to act on UDP-glucose and UDP-acetylglucosamine.

A similar enzyme was isolated from wheat germ by Dankert, Gonçalves \& Recondo (1964). In this case the compound that reacts faster is ADPglucose, as follows:

ADP-glucose + inorganic phosphate

$$
\rightarrow \text { ADP + glucose 1-phosphate }
$$

The rates obtained with other compounds were approximately as follows (rate with ADP-glucose taken as 100): deoxyADP-glucose, 70; ADPmannose, 50; ADP-xylose, 10.

\section{Epimerization}

As mentioned above the first reaction of a nucleoside diphosphate sugar to be studied was the 4epimerization of UDP-glucose to give UDPgalactose (Leloir, 1951). This reaction has been the object of many studies (Kalckar, 1958). An important finding (Maxwell, 1956) was that the process requires catalytic amounts of $\mathrm{NAD}$, so that it can be assumed that some kind of oxidoreduction takes place. 
Besides the enzyme that catalyses the UDPglucose-UDP-galactose interconversion many others have been discovered. Thus enzymes catalysing the interconversion of the following pairs are known:

UDP-glucuronic acid $\rightarrow$ UDP-galacturonic acid (Neufeld, Feingold \& Hassid, 1958; Smith, Mills, Bernheimer \& Austrian, 1958)

UDP-D-xylose $\rightarrow$ UDP-L-arabinose (Ginsburg, Neufeld \& Hassid, 1956)

UDP-glucosamine $\rightarrow$ UDP-galactosamine (Maley \& Maley, 1959)

UDP-acetylglucosamine $\rightarrow$ UDP-acetylgalactosamine (Glaser, 1959)

TDP-acetylglucosamine $\rightarrow$ TDP-acetylgalactosamine (Kornfeld \& Glaser, 1962)

Besides 4-epimerization two other types have been described. One is a 2-epimerization, as follows (Roseman, 1962b) :

UDP-acetylglucosamine

$$
\rightarrow \text { acetylmannosamine + UDP }
$$

It is not known whether UDP-acetylmannosamine is an intermediate in the reaction. The conversion requires inversion at $\mathrm{C}-2$, i.e. of the acetamido group. This is a unique case and nothing is known about the mechanism.

Another interesting case is the interconversion of UDP-D-glucuronic acid into UDP-L-iduronic acid (Jacobson \& Davidson, 1963). In this case the inversion is at C-5.

\section{Deoxyhexose formation}

A more complicated process leads to the formation of deoxyhexoses from hexoses. Two cases have been studied in some detail. One is:

$$
\text { GDP-D-mannose } \rightarrow \text { GDP-L-fucose }
$$

This process was studied by Ginsburg (1958) and involves an inversion at C-3 and C-5 and reduction at $\mathrm{C}-6$. The other case is:

$$
\text { TDP-D-glucose } \rightarrow \text { TDP-L-rhamnose }
$$

It has been studied by Glaser \& Kornfeld (1961) and Pazur \& Shuey (1961) and involves inversion at $\mathrm{C}-3, \mathrm{C}-4$ and $\mathrm{C}-5$ plus reduction at C-6. A similar process seems to occur in plants, but with UDP instead of TDP (Barber, 1962a).

In both cases of deoxyhexose formation intermediates have been detected which are 6-deoxy-4oxo derivatives of the original hexose. It seems that the first step is the oxidation at C-4 and reduction at C-6. It is an internal oxidoreduction, which requires NAD. The inversions at C-3 and C-5 are supposed to take place by an enediol transformation as for that of fructose into glucose or mannose, where a double bond is believed to be formed. The last step is a reduction at $\mathrm{C}-4$ with $\mathrm{NADPH}_{2}$, so that a 6-deoxyhexose is formed.

For the glucose-rhamnose interconversion there is an inversion at C-4, as for the glucose-galactose transformation; i.e. after oxidation to the 4-oxo compound there is a reduction, but the position of the hydroxyl group is changed.

A reaction related to the previous ones and involving a C-3 and C-5 inversion is assumed by $\mathrm{Su} \&$ Hassid (1962) to occur in the formation of GDP-Lgalactose from GDP-D-mannose. The formation of a 3,6-dideoxyhexose, colitose, from GDP-mannose has been reported (Heath \& Elbein, 1962). This involves reduction at $\mathrm{C}-3$ and $\mathrm{C}-6$ and inversion at position C-4.

\section{Oxidation}

Another important transformation of nucleoside diphosphate sugars is the oxidation at C-6. The first case to be studied was the oxidation of UDP. glucose to UDP-glucuronic acid, which was obtained by Strominger, Kalckar, Axelrod \& Maxwell (1954) with a liver enzyme. The reaction product had already been isolated by Storey \& Dutton (1955) as a cofactor of glucuronidation. The oxidation takes place with NAD as oxidant and no intermediate has been detected, although one would expect that the primary alcohol group should first be transformed into an aldehyde and then into a carboxyl group. The enzyme has also been found in plants (Strominger \& Mapson, 1957). Further, an enzyme that catalyses the oxidation of GDP-mannose to GDP-mannuronic acid has been found in certain bacteria, which form mannuronic acid polymers (Preiss, 1962).

\section{UDP-glucose as donor}

After Dutton \& Storey (1953) found the enzyme in liver that catalyses the transfer of glucuronic acid from UDP-glucuronic acid to phenols and other substances, it became evident that nucleoside diphosphate sugars might be involved in other transfer reactions. In 1953, the synthesis of trehalose phosphate (Leloir \& Cabib, 1953; Cabib \& Leloir, 1958) was described according to the reaction:

UDP-glucose + glucose 6-phosphate

$$
\rightarrow \text { UDP + trehalose phosphate }
$$

The enzyme is usually accompanied by a specific phosphatase; this leads to the formation of free trehalose, which is found in yeasts, fungi and insects.

Soon after, two other enzymes were found in plants which give rise to free sucrose (Cardini, Leloir \& Chiriboga, 1955) and sucrose phosphate (Leloir \& Cardini, 1955) as follows:

$$
\text { UDP-glucose + fructose } \rightarrow \text { sucrose + UDP }
$$


UDP-glucose + fructose 6-phosphate

$$
\rightarrow \text { sucrose phosphate + UDP }
$$

Sucrose synthesis in vitro was obtained by Hassid, Doudoroff and others (Hassid \& Doudoroff, $1950 a, b)$ with a bacterial enzyme as follows:

Glucose 1-phosphate + fructose

$$
\rightarrow \text { sucrose + inorganic phosphate }
$$

There is a considerable difference in the equilibrium of the two reactions. That of sucrose phosphorylase (eqn. 17) has an equilibrium displaced in the direction of phosphorolysis (decomposition of sucrose), whereas that in which UDP-glucose is the donor (eqn. 15) has an equilibrium displaced in the direction of synthesis. It seems that sucrose phosphorylase and probably all phosphorylases are used in the degradation of their substrates.

UDP-glucose is also used as donor in the formation of glycosides. Tabone and co-workers (Tabone, 1955; Jacobelli, Tabone \& Tabone, 1958) first described the enzyme that catalyses the reaction:

\section{UDP-glucose + anthranilic acid}

$\rightarrow 0$-aminobenzoic acid glucoside + UDP

The process has been studied extensively by Cardini and co-workers (Cardini \& Leloir, 1957; Cardini \& Yamaha, 1958; Yamaha \& Cardini, 1960), who isolated plant enzymes which catalyse reactions (19) and (20):

$$
\text { UDP-glucose + quinol } \rightarrow \text { arbutin + UDP }
$$

UDP-glucose + arbutin

$$
\rightarrow \text { quinol gentiobioside + UDP }
$$

Another transfer reaction that should be mentioned is the glucosylation of hydroxymethylcytosine of the deoxyribonucleic acid of virusinfected $E$. coli. Either one glucose residue or two residues (forming a disaccharide) can be transferred and the linkage formed can be $\alpha$ or $\beta$ (Jossé \& Kornberg, 1962).

Polysaccharides from UDP-glucose. Several important homopolysaccharides are formed by the transfer of glucose from UDP-glucose. These are: glycogen in animals, callose in plants, cellulose in some bacteria and paramylon in Euglena gracilis.

The enzyme that leads to the synthesis of glycogen (glycogen synthetase or UDP-glucoseglycogen glucosyltransferase) was first detected six years ago (Leloir \& Cardini, 1957; Leloir, Olavarría, Goldemberg \& Carminatti, 1959) and is being studied actively because of its physiological interest. It catalyses the reaction:

$$
\begin{aligned}
& \text { UDP-glucose }+ \text { (glucose) }{ }_{n} \\
& \quad \rightarrow \text { UDP + glucosyl- } \alpha-(1 \rightarrow 4) \text {-(glucose })_{n}
\end{aligned}
$$

The acceptor (glucose) $)_{n}$ may be represented by oligosaccharides. For the $\alpha-(1 \rightarrow 4)$-linked oligosaccharides such as maltotetraose or maltohexaose the affinity is much lower than for glycogen (Goldemberg, 1962). Thus, in order to give the same rate of reaction, the oligosaccharide concentration has to be about 100 times as high. This is when glycogen is expressed in moles of nonreducing end-groups per litre. Maltotriose is hardly used as an acceptor and maltose may give some reaction, but this is within the limits of error of the methods.

Glycogen synthetase is strongly activated by glucose 6-phosphate. The concentration that gives half-maximal activation is $0.6 \mathrm{~mm}$, which is similar to the concentration occurring in tissues. It is likely therefore that in vivo glucose 6-phosphate regulates the activity of the enzyme.

The yeast enzyme has been carefully studied by Algranati \& Cabib (1962). It differs from that of muscle in that it is less activated by glucose 6 phosphate and does not use oligosaccharides as acceptors.

Another glucan that is formed from UDPglucose is callose. This is a $\beta-(1 \rightarrow 3)$-glucose polymer found in plants, where it appears to have importance in wound-healing and in the formation of the sieve plates that regulate the passage of sap through the tubes. Hassid and co-workers (Feingold, Neufeld \& Hassid, 1958) prepared a partially purified preparation from mung bean which catalysed callose synthesis and which did not require any added acceptor.

Another $\beta-(1 \rightarrow 3)$-linked glucan is paramylon, which is the reserve carbohydrate of Euglena. It occurs in this organism as small insoluble grains, somewhat similar to starch grains. An enzyme has been prepared by Goldemberg \& Marechal (1963) which catalyses transfer from UDP-glucose. No added acceptor is necessary. In this synthesis, several UDP-glucose analogues were tested with negative results. These were ADP-glucose, deoxyADP-glucose and UDP- $\beta$-glucose (Goldemberg \& Marechal, 1963).

Finally it should be mentioned that Glaser (1957) prepared an enzyme from Acetobacter which catalyses transfer from UDP-glucose to cellulose $[\beta-(1 \rightarrow 4)$-glucan $]$. No such system has yet been prepared from plants.

\section{UDP-galactose as donor}

As mentioned above, our interest in galactose metabolism originated in studies on lactose synthesis. However, we became interested in other things and abandoned the problem. Several other workers have made important contributions. Clear results were obtained by Watkins \& Hassid (1961), who prepared a particulate enzyme from the mammary gland which catalyses the reaction:

$$
\text { UDP-galactose + glucose } \rightarrow \text { UDP + lactose }
$$


A pathway involving $\alpha$-glucose 1-phosphate as acceptor had been proposed by Gander, Petersen \& Boyer (1957), but it did not agree with the experiments of Wood, Schambye \& Peeters (1957), in which the labelling of lactose from different precursors had been studied. These studies indicated that lactose is formed from free glucose as in eqn. (22).

Another reaction that uses UDP-galactose (Cleland \& Kennedy, 1960) is catalysed by a brain enzyme as follows:

UDP-galactose + sphingosine

$$
\rightarrow \text { psychosine + UDP }
$$

\section{ADP-glucose as donor}

After it was found that the enzyme which catalyses glycogen synthesis is strongly adsorbed to glycogen (Leloir \& Goldemberg, 1960), similar investigations were carried out with plant tissues and it was found that starch grains contain an enzyme which catalyses transfer of glucose from UDP. glucose to starch (de Fekete, Leloir \& Cardini, 1960). If the reaction was carried out with UDPglucose labelled in the glucose portion and the amylose and amylopectin components were separated, the label was found in both fractions. Transfer also took place to added oligosaccharides. Thus the next higher homologues were formed from maltose, maltotriose, maltotetraose or maltopentaose. It appears therefore that the enzyme is not very specific for the acceptor, so that any compound of two or more $\alpha$ - $(1 \rightarrow 4)$-linked glucose units can serve as acceptor (Leloir, de Fekete \& Cardini, 1961).

The Michaelis constant for UDP-glucose was found to be $600 \mathrm{~mm}$; this is a very high value in comparison with those for other enzymes, which are usually 0.1-1 mM. This high value for the $K_{m}$ was attributed to permeability factors, which might hinder the access of UDP-glucose to the active site of the enzyme. Another possibility considered was that UDP-glucose might not be the right substrate. This possibility could be explored because the preparation of synthetic nucleoside diphosphate sugars has become easy, thanks to the methods developed by Khorana and co-workers (Roseman, Distler, Moffatt \& Khorana, 1961), in which hexose 1-phosphates are caused to react with the nucleotide morpholidate. Many nucleoside diphosphate sugars prepared by Dr Recondo (Recondo \& Leloir, 1961) were tested with starch synthetase. Many of them were inactive, e.g. ADP-maltose, CDP-glucose, IDP-glucose, GDPglucose, ADP-galactose, UDP-galactose, the $\beta$ anomers of ADP-glucose and UDP-glucose and an isomer of ADP-glucose in which the glucose is joined to ADP through C-6. But one of them was a good substrate. This was ADP-glucose (Fig. 1), which reacts with the enzyme ten times as rapidly as UDP-glucose (Recondo \& Leloir, 1961).

The fact that ADP-glucose is a better substrate than UDP-glucose for starch synthetase raised the problem whether it is present in plant tissues. Espada (1962) was able to isolate an enzyme from wheat which catalyses the reaction:

$$
\begin{aligned}
& \text { ATP }+\alpha \text {-glucose 1-phosphate } \\
& \quad \rightarrow \text { ADP-glucose + inorganic pyrophosphate }
\end{aligned}
$$

The enzyme is different from the similar one that catalyses UDP-glucose synthesis. If there is an enzyme that forms ADP-glucose from ATP and $\alpha$-glucose 1-phosphate, and, since the latter two substances are known to be present in plant tissues, it seemed highly probable that ADPglucose is a plant constituent. More evidence on this point was obtained by Kauss \& Kandler (1962). They administered ${ }^{14} \mathrm{CO}_{2}$ to Chlorella in the light. Extracts of such cells were found to contain a labelled substance which co-chromatographed with synthetic ADP-glucose. Kauss \& Kandler (1962) also measured changes with time and concluded that the ADP-glucose pool is saturated earlier than the UDP-glucose pool and that starch takes ${ }^{14} \mathrm{C}$ earlier than sucrose. They concluded that in vivo ADP-glucose is involved in starch synthesis and UDP-glucose in that of sucrose. Recent work in our Laboratory (Recondo, Dankert \& Leloir, 1963) has resulted in the isolation of ADP-glucose from fresh maize seeds.

One question that arises is: which is the natural substrate for starch synthesis in vivo? From the scanty evidence available the answer is that both UDP-glucose and ADP-glucose are involved and probably in about equal proportions, because although UDP-glucose reacts more slowly (about one-tenth the rate) its concentration is higher (about 5-10 times). This would result in about the same rate of transfer.

ADP-glucose has been tested with other enzymes. The rate of reaction with different synthetases was as follows (rate with UDP-glucose, 1): starch 10, glucosides 1.5 (Trivelloni, Recondo \& Cardini, 1962); sucrose 0.8 (Cardini \& Recondo, 1962); glycogen 0.5 (Goldemberg, 1962). We have tried to detect ADP-glucose pyrophosphorylase in animal tissues, with negative results, and at present there is no evidence that ADP-glucose occurs in animals.

\section{Other donors}

Many transfer reactions have been investigated, but only a few may be mentioned as examples: Barber (1962 $b$ ) found that the reaction:

TDP-L-rhamnose + 3-quercetin $\beta$-D-glucoside

$$
\rightarrow \text { rutin + TDP }
$$


is catalysed by a mung-bean enzyme. Later he tried UDP-rhamnose as donor and found that it was more active. Further, he found enzymes in plants which catalyse the series of reactions from UDP-glucose to UDP-rhamnose (Barber, 1962a). This is an interesting finding, since in bacteria rhamnose formation takes place from TDPglucose and not from UDP-glucose.

Enzymes have been obtained from various sources which catalyse different types of transfer reactions. Thus asparagus extracts lead to the formation of xylans from UDP-xylose (Feingold, Neufeld \& Hassid, 1959). Chitin is formed by extracts of Neurospora with UDP-acetylglucosamine as donor (Glaser \& Brown, 1957). Extracts of certain bacteria catalyse rhamnose-transfer from TDP-rhamnose to lipid (Burger, Glaser \& Burton, 1962) or to polysaccharide (Zeleznick, Boltralik, Barkulis, Smith \& Heymann, 1962).

An enzyme can be obtained from the mammary gland (Jourdian, Carlson \& Roseman, 1963) which will transfer the carbohydrate moiety of CMPneuraminic acid to lactose, giving neuraminlactose, a compound first isolated by Caputto $\&$ Trucco (1952).

Recently Algranati, Carminatti \& Cabib (1963) have obtained a transfer of mannose residues from GDP-mannose to mannan with yeast enzymes.

\section{Heteropolysaccharides}

The biosynthesis of heteropolysaccharides is still more complicated and more interesting than that of homopolysaccharides. The composition and type of linkage are determined by the specificity of the transferring enzymes. Thus for the synthesis of hyaluronic acid presumably two enzymes are needed, one transferring glucuronic acid from UDP-glucuronic acid to $\mathrm{C-3}$ of an acetylglucosamine residue, and another enzyme that would transfer acetylglucosamine from UDP-acetylglucosamine to C-4 of a glucuronic acid residue. In this manner a chain of alternating acetylglucosamine and glucuronic acid residues would be formed. The process has been studied by Dorfman and co-workers (Dorfman, 1962), who obtained an enzyme from Streptococcus haemolyticus which catalyses the formation of hyaluronic acid from UDP. sugars. The enmzye was bound to particles that presumably had their origin in the cell membrane.

A similar process, the synthesis of the capsular substance of Pneumococcus, has been studied by Mills \& Smith (1962). With type III Pneumococcus polysaccharide the necessary substrates were UDPglucose and UDP-glucuronic acid, and the polysaccharide synthesized could be precipitated with the corresponding antibody. This will be a very fertile field in immunochemistry, since about 80 different types of pneumococci can be distinguished with antisera.

Some very interesting results, which bear on the determination of specificity, have been obtained by Nikaido (1962) and Osborn, Rosen, Rothfield \& Horecker (1962) in a study on Salmonella. The wild type of this organism has a cell-wall lipopolysaccharide that contains glucose, galactose, mannose, rhamnose, dideoxyhexoses and an aldoheptose. A mutant that lacks UDP-galactose 4-epimerase has a lipopolysaccharide in which all these sugars except glucose and aldoheptose are lacking. Mutants grown in galactose have a lipopolysaccharide nearly the same as that of the wild type. Different explanations for these facts were investigated by Nikaido and co-workers (Nikaido, 1961; Fukasawa \& Nikaido, 1961; Nikaido \& Jokura, 1961) and it was concluded that the wild-type polysaccharide has a glucose core on which the other sugar residues are attached. The mutant has no UDP-galactose, so that no galactose can be transferred to the glucose core. In the absence of galactose residues, none of the other sugars can be attached to the polysaccharide core. In accordance with this, mutants were found to accumulate CDP-dideoxyhexoses and TDP-rhamnose, which are presumably the donors of dideoxyhexoses and rhamnose residues.

The synthesis of other polysaccharides may presumably take place by transference of complex units instead of monosaccharides. In some cases a monosaccharide phosphate might be transferred. A closely related process is the synthesis of ribitol phosphate (Glaser, 1963) and glycerol phosphate polymers (Burger \& Glaser, 1962), which presumably occurs by transference to an acceptor $\mathbf{A}$ as follows:

$$
\begin{aligned}
& \text { CDP-ribitol + A } \rightarrow \text { ribitol phosphate-A + CMP (26) } \\
& \text { CDP-glycerol + A } \rightarrow \text { glycerol phosphate-A + CMP }
\end{aligned}
$$

A similar reaction with GDP-mannose as substrate might lead to the formation of mannose phosphate polymers by some yeast (Slodki, 1962, 1963).

In some cases it is likely that disaccharides or complex saccharides are transferred. Several compounds that may act in this way have been isolated, such as Park's (1952) compounds in which UDP-acetylmuramic acid (3-O-lactoylacetylglucosamine) is joined to one or more amino acid residues. They are believed to be involved in cell-wall synthesis (Strominger, 1962a). Other compounds that presumably can act as donors of complex saccharides are the UDP-derivatives of acetyl-lactosamine and acetyl-lactosamine fucoside (Kobata, 1962), acetylglucosamine fucoside (Takahashi \& Suzuki, 1962), acetylglucosamine phosphogalactose 
(Strominger, 1962b; Suzuki, 1962; Gabriel \& Ashwell, 1962), acetylglucosamine 4-sulphate (Strominger, 1962b) and lactosamine joined to $N$ acetylneuraminic acid (Jourdian, Shimizu \& Roseman, 1961).

\section{Conclusion}

The discovery of nucleoside diphosphate sugars has led to great advances in the study of the interconversion of sugars and polysaccharide synthesis. It seems that we now know in general how polysaccharides are formed. However, in many cases the experiments have not gone further than the transference of some radioactivity from highly labelled substrates. We have not been able to solve a problem that seems simple, such as the preparation of a starch grain in vitro. This should be possible in the near future and we might become more ambitious and try to obtain bacterial or plantcell walls with their characteristic shapes.

\section{REFERENCES}

Algranati, I. D. \& Cabib, E. (1962). J. biol. Chem. 237, 1007. Algranati, I. D., Carminatti, H. \& Cabib, E. (1963). Biochem. biophys. Res. Commun. 12, 504.

Baddiley, J. (1962). Fed. Proc. 21, 1084.

Barber, G. A. (1962a). Biochem. biophys. Res. Commun. 8, 204.

Barber, G. A. (1962b). Biochemistry, 1, 463.

Burger, M. M. \& Glaser, L. (1962). Biochim. biophys. Acta, 64, 575.

Burger, M., Glaser, L. \& Burton, R. M. (1962). Biochim. biophys. Acta, 56, 172.

Cabib, E. (1963). Annu. Rev. Biochem. 32, 321.

Cabib, E. \& Leloir, L. F. (1954). J. biol. Chem. 206, 779.

Cabib, E. \& Leloir, L. F. (1958). J. biol. Chem. 231, 259.

Caputto, R., Leloir, L. F., Cardini, C. E. \& Paladini, A. C. (1950). J. biol. Chem. 184, 333.

Caputto, R., Leloir, L. F. \& Trucco, R. E. (1948). Enzymologia, 12, 350.

Caputto, R., Leloir, L. F., Trucco, R. E., Cardini, C. E. \& Paladini, A. C. (1948). Arch. Biochem. 18, 201.

Caputto, R. \& Trucco, R. E. (1952). Nature, Lond., 169, 1061.

Cardini, C. E. \& Leloir, L. F. (1957). Cienc. e Invest. 13, 514.

Cardini, C. E., Leloir, L. F. \& Chiriboga, J. (1955). J. biol. Chem. 214, 149.

Cardini, C. E., Paladini, A. C., Caputto, R. \& Leloir, L. F. (1950). Nature, Lond., 165, 191.

Cardini, C. E., Paladini, A. C., Caputto, R., Leloir, L. F. \& Trucco, R. E. (1949). Arch. Biochem. $22,87$.

Cardini, C. E. \& Recondo, E. (1962). Plant \& Cell Physiol., Tokyo, 3, 313.

Cardini, C. E. \& Yamaha, T. (1958). Nature, Lond., 182, 1446.

Carlson, D. M. \& Hansen, R. G. (1961). Fed. Proc. 20, 84.

Carminatti, H. \& Cabib, E. (1961). Biochim. biophys. Acta, 53, 417.

Cleland, W. W. \& Kennedy, E. P. (1960). J. biol. Chem. 235, 45 .

Dankert, M., Gonçalves, I. R. J. \& Recondo, E. (1964). Biochim. biophys. Acta 81, 78. de Fekete, M. A. R., Leloir, L. F. \& Cardini, C. E. (1960). Nature, Lond., 187, 918.

Dorfman, A. (1962). Fed. Proc. 21, 1070.

Dutton, G. J. \& Storey, I. D. E. (1953). Biochem. J. 53 xxxvii.

Espada, J. (1962). J. biol. Chem. 237, 3577.

Feingold, D. S., Neufeld, E. F. \& Hassid, W. Z. (1958). J. biol. Chem. 233, 783.

Feingold, D. S., Neufeld, E. F. \& Hassid, W. Z. (1959). J. biol. Chem. 234, 488.

Fukasawa, T. \& Nikaido, H. (1961). Biochim. biophys. Acta, 48, 470.

Gabriel, O. \& Ashwell, G. (1962). J. biol. Chem. 237, 1400.

Gander, J. E., Petersen, W. E. \& Boyer, P. D. (1957). Arch. Biochem. Biophys. 69, 85.

Ginsburg, V. (1958). J. Amer. chem. Soc. 80, 4426.

Ginsburg, V., Neufeld, E. F. \& Hassid, W. Z. (1956). Proc. nat. Acad. Sci., Wash., 42, 333.

Glaser, L. (1957). Biochim. biophys. Acta, 25, 436.

Glaser, L. (1959). Biochim. biophys. Acta, 31, 575.

Glaser, L. (1963). Biochim. biophys. Acta, 71, 237.

Glaser, L. \& Brown, D. H. (1957). Biochim. biophys. Acta, 23, 449 .

Glaser, L. \& Kornfeld, S. (1961). J. biol. Chem. 236, 1795.

Goldemberg, S. H. (1962). Biochim. biophys. Acta, 56, 357.

Goldemberg, S. H. \& Marechal, L. R. (1963). Biochim. biophys. Acta, 71, 743.

Hashimoto, T., Tatibana, M., Ishii, Y. \& Yoshikawa, H. (1961). J. Biochem., Tokyo, 50, 548.

Hassid, W. Z. \& Doudoroff, M. (1950a). Advanc. Enzymol. $10,123$.

Hassid, W. Z. \& Doudoroff, M. (1950b). Advanc. Carbohyd. Chem. 5, 25.

Heath, E. C. \& Elbein, A. D. (1962). Proc. nat. Acad. Sci., Wash., 48, 1209.

Jacobelli, G., Tabone, M. J. \& Tabone, D. (1958). Bull. Soc. Chim. biol., Paris, 40, 955.

Jacobson, B. \& Davidson, E. A. (1963). Biochim. biophys. Acta, 73, 145 .

Jossé, J. \& Kornberg, A. (1962). J. biol. Chem. 237, 1968.

Jourdian, G. W., Carlson, D. M. \& Roseman, S. (1963). Biochem. biophys. Res. Commun. 10, 352.

Jourdian, G. W., Shimizu, F. \& Roseman, S. (1961). Fed. Proc. 20, 161.

Kalckar, H. M. (1958). Advanc. Enzymol. 20, 111.

Kalckar, H. M., Braganca, M. \& Munch-Petersen, A. (1953). Nature, Lond., 172, 1038.

Kauss, H. \& Kandler, O. (1962). Z. Naturf. 17, 858.

Kobata, A. (1962). Biochem. biophys. Res. Commun. 7, 134.

Kornfeld, S. \& Glaser, L. (1961). J. biol. Chem. 236, 1791.

Kornfeld, S. \& Glaser, L. (1962). J. biol. Chem. 237, 3052.

Kosterlitz, H. W. (1943). Biochem. J. 37, 318.

Leloir, L. F. (1951). Arch. Biochem. Biophys. 33, 186.

Leloir, L. F. \& Cabib, E. (1953). J. Amer. chem. Soc. 75, 5445.

Leloir, L. F. \& Cardini, C. E. (1955). J. biol. Chem. 214, 157.

Leloir, L. F. \& Cardini, C. E. (1957). J. Amer. chem. Soc. $79,6340$.

Leloir, L. F., de Fekete, M. A. R. \& Cardini, C. E. (1961). J. biol. Chem. 236, 636.

Leloir, L. F. \& Goldemberg, S. H. (1960). J. biol. Chem. 235, 919.

Leloir, L. F., Olavarría, J. M., Goldemberg, S. H. \& Carminatti, H. (1959). Arch. Biochem. Biophys. 81, 508. 
Leloir, L. F., Trucco, R. E., Cardini, C. E., Paladini, A. C. \& Caputto, R. (1948). Arch. Biochem. 19, 339.

Maley, F. \& Maley, G. F. (1959). Biochim. biophys. Acta, 31, 577.

Maley, F., Maley, G. F. \& Lardy, H. A. (1956). J. Amer. chem. Soc. 78, 5303.

Maxwell, E. S. (1956). J. Amer. chem. Soc. 78, 1074.

Mills, G. T., Ondarza, R. \& Smith, E. E. B. (1954). Biochim. biophys. Acta, 14, 159.

Mills, G. T. \& Smith, E. E. B. (1962). Fed. Proc. 21, 1089. Munch-Petersen, A. (1956). Acta chem. scand. 10, 928.

Munch-Petersen, A., Kalckar, H. M., Cutolo, E. \& Smith, E. E. B. (1953). Nature, Lond., 172, 1036.

Neufeld, E. F., Feingold, D. S. \& Hassid, W. Z. (1958). J. Amer. chem. Soc. 80, 4430.

Neufeld, E. F., Ginsburg, V., Putman, E. W., Fanshier, D. \& Hassid, W. Z. (1957). Arch. Biochem. Biophys. 69, 602.

Nikaido, H. (1961). Biochim. biophys. Acta, 48, 460.

Nikaido, H. (1962). Proc. nat. Acad. Sci., Wash., 48, 1542.

Nikaido, H. \& Jokura, K. (1961). Biochem. biophys. Res. Commun. 6, 304.

Osborn, M. J., Rosen, S. M., Rothfield, L. \& Horecker, B. L. (1962). Proc. nat. Acad. Sci., Wash., 48, 1831.

Park, J. T. (1952). J. biol. Chem. 194, 877, 885, 897.

Park, J. T. \& Johnson, M. J. (1949). J. biol. Chem. 179, 585.

Pazur, J. H. \& Shuey, E. W. (1961). J. biol. Chem. 236, 1780.

Preiss, J. (1962). Biochem. biophys. Res. Commun. 9, 235.

Recondo, E., Dankert, M. \& Leloir, L. F. (1963). Biochem. biophys. Res. Commun. 12, 204.

Recondo, E. \& Leloir, L. F. (1961). Biochem. biophys. Res. Commun. 6, 85.

Roseman, S. (1962a). Proc. nat. Acad. Sci., Wash., 48, 437. Roseman, S. (1962b). Fed. Proc. 21, 1075.
Roseman, S., Distler, J. J., Moffatt, J. G. \& Khorana, H. G. (1961). J. Amer. chem. Soc. 83, 659.

Shaw, D. R. D. (1962). Biochem. J. 82, 297.

Slodki, M. E. (1962). Biochim. biophys. Acta, 57, 525.

Slodki, M. E. (1963). Biochim. biophys. Acta, 69, 96.

Smith, E. E. B., Mills, G. T., Bernheimer, H. P. \& Austrian, R. (1958). Biochim. biophys. Acta, 29, 640.

Smith, E. E. B., Munch-Petersen, A. \& Mills, G. T. (1953). Nature, Lond., 172, 1038.

Storey, I. D. E. \& Dutton, G. J. (1955). Biochem. J. 59, 279.

Strominger, J. L. (1962a). Fed. Proc. 21, 134.

Strominger, J. L. (1962b). J. biol. Chem. 237, 1388.

Strominger, J. L., Kalckar, H. M., Axelrod, J. \& Maxwell, E. S. (1954). J. Amer. chem. Soc. 76, 6411.

Strominger, J. L. \& Mapson, L. W. (1957). Biochem. J. 66, 567.

Su, C. C. \& Hassid, W. Z. (1962). Biochemistry, 1, 468.

Suzuki, S. (1962). J. biol. Chem. 237, 1393.

Tabone, D. (1955). C.R. Acad. Sci., Paris, 241, 1521.

Takahashi, N. \& Suzuki, S. (1962). Biochim. biophys. Acta, 63, 344.

Trivelloni, J. C., Recondo, E. \& Cardini, C. E. (1962). Nature, Lond., 195, 1202.

Trucco, R. E., Caputto, R., Leloir, L. F. \& Mittelman, N. (1948). Arch. Biochem. 18, 137.

Warren, L. \& Blacklow, R. S. (1962). Biochem. biophys. Res. Commun. 7, 433.

Watkins, W. M. \& Hassid, W. Z. (1961). Biochem. biophys. Res. Commun. 5, 260.

Wood, H. G., Schambye, P. \& Peeters, G. J. (1957). J. biol. Chem. 226, 1023.

Yamaha, T. \& Cardini, C. E. (1960). Arch. Biochem. Biophys. 86, 127, 133.

Zeleznick, L. D., Boltralik, J. J., Barkulis, S. S., Smith, C. \& Heymann, H. (1962). Science, 140, 400.

Biochem. J. (1964) 91, 8

\title{
The Metabolism of Hydroxylamine to Nitrite by Nitrosomonas
}

\author{
BY J. H. ANDERSON \\ Long Ashton Research Station, University of Bristol
}

(Received 2 May 1963)

Hofman \& Lees (1953) found that washed-cell suspensions of the autotrophic micro-organism Nitrosomonas, which derives the energy required for growth from the oxidation of ammonia to nitrite, was capable of metabolizing hydroxylamine to nitrite. Lees (1954) proposed that the metabolism of ammonia to nitrite proceeded via hydroxylamine and an unknown intermediate in a series of three two-electron steps in which the energy and reducing power released could be efficiently utilized by the cell. Since hyponitrite, $\mathrm{H}_{2} \mathrm{~N}_{2} \mathrm{O}_{2}$, was not metabolized to nitrite, he suggested that the hypothetical intermediate was nitroxyl, (NOH). Since the free energy released by the oxidation of ammonia to hydroxylamine was small, the metabolism of hydroxylamine to nitrite provided the main free-energy requirements of the cell.

Nicholas \& Jones (1960) found that cell-free extracts produced nitrite from hydroxylamine aerobically in the presence of mammalian cytochrome $c$. The enzymic reduction of the cytochrome by hydroxylamine was inhibited by mepacrine (Falcone, Shug \& Nicholas, 1962). The reversal by FAD of the inhibition suggests that a flavin was involved.

Whole or crushed cells reduced methylene blue anaerobically in the presence of hydroxylamine; the disappearance of hydroxylamine was accom- 